\title{
EDITORIAL
}

\section{Classic Reflection in Best Evidence in Chinese Education}

\author{
Editorial Office of Best Evidence in Chinese Education
}

$I^{2}$

$\mathrm{N}$ the long history of educational development, many representative figures have emerged, and many representative works and expositions have been circulating. These characters and discourses have had a huge impact on the development of education. Plato's Utopia, Comenius's Large Teaching Theory, and Dewey's Democracy and Education were representative of them.

Many commendable representative figures and discourses have also appeared in the history of China's education development. For example, the world's earliest educational monograph Xue $J i$ was born in China. Seriously studying these celebrities' masterpieces is of great practical significance to the development of today's education, helping us to further understand the relationship between history and modernity, and to understand the inheritance and innovation of the development of contemporary education.

As an academic educational journal, Best Evidence in Chinese Education is dedicated to the introduction of Chinese educational practice and research results; the journal offers a new column of "Classic Reflection". It is an attempt to introduce the best modern Chinese education researchers and their representative works to the world through this column, in order to let the world better understand the results of China's educational practice and research.

Due to the differences between Eastern and Western cultures and education systems, many researches in China focus on different issues from those of the West. These research results may be somewhat different from Western research methods in research methods, but these research results point to the same, that is, in order to enable the next generation to receive better education and cultivate more talents for the development of human society. These results are a long time ago, but due to the limitations of the specific language

(C) 2021 Insights Publisher. All rights reserved.

(C) (i) $($ Creative Commons Non Commercial CC BY-NC: This article is distributed under the terms of the Creative Commons Attribution-NonCommercial 4.0 License

(http://www.creativecommons.org/licenses/by-nc/4.0/) which permits non-commercial use, reproduction and distribution of the work without further permission provided the original work is attributed by the Insights Publisher. 
of the original journal, these research results may not be widely understood by the world. For this reason, the editorial office of the journal welcomes researchers from all over the world to recommend the outstanding researches of outstanding Chinese scholars to the journal, and they will be published in English to spread them out for the world.

The journal would like to express its sincere gratitude to the authors of these outstanding results, and also to the original contributions of those outstanding research results!

Correspondence to: Editorial Office Best Evidence in Chinese Education United States of America Email: editorial.office@bonoi.org

Conflict of Interests: None. Doi: 10.15354/bece.21.e026 